\title{
Wich factors influencing the number of teeth at 12 months of age: a birth cohort study
}

\author{
Ethieli Rodrigues da SILVEIRA ${ }^{(a)}$ \\ Mariana Gonzalez \\ CADEMARTORI(a) \\ Thiago Machado ARDENGHI(b) \\ Mariangela Freitas SILVEIRA(c) iD \\ Fernando Celso BARROS(c) iD \\ Marina Sousa AZEVEDO(a) iD \\ Flávio Fernando DEMARCO(a) iD \\ (a) Universidade Federal de Pelotas - UFPel, \\ Dental School, Department of Pediatric \\ Dentistry, Pelotas, RS, Brazil. \\ (b) Universidade Federal de Santa Maria \\ - UFSM, Dental School, Department of \\ Pediatric Dentistry, Santa Maria, RS, Brazil \\ (c) Universidade Federal de Pelotas - \\ UFPel, Medical School, Department of \\ Epidemiology, Pelotas, RS, Brazil.
}

Declaration of Interests: The authors certify that they have no commercial or associative interest that represents a conflict of interest in connection with the manuscript.

Corresponding Author:

Flávio Fernando Demarco

E-mail: ffdemarco@gmail.com

https://doi.org/10.1590/1807-3107bor-2021.vol35.0059

Submitted: May 31, 2020

Accepted for publication: October 22,2 020

Last revision: November 17, 2020
Abstract: This study aimed to verify, through a longitudinal follow-up, the pre-, peri- and postnatal factors associated with the eruption of deciduous teeth. The study was nested in a Birth Cohort Study conducted in Pelotas, a Southern Brazilian city. Mothers were followed prenatally and their children were followed-up perinatally, at 3 and 12 months of age. The outcome was the number of teeth at 12 months, and exploratory variables included maternal habits and characteristics, anthropometric measures of children and mothers, and socioeconomic and demographic information. Data were collected through interviews with the mother and children's clinical exam. Poisson regression models were used for the analysis. Participants included 4,014 children with a mean number of erupted teeth at 12 months of 5.50. After adjustments, a lower mean number of teeth was observed in children from non-white mothers, early preterm children, and shorter children at birth and at 12 months. A higher number of teeth was observed for mothers with excessive weight gain during pregnancy, mothers who smoked during pregnancy, weightier children at birth and at 12 months, and for children with larger heads at birth and at 12 months. Our findings suggest that maternal and children characteristics influenced primary tooth eruption.

Keywords: Tooth Eruption; Epidemiology; Cohort Studies; Tooth, Deciduous.

\section{Introduction}

Dental eruption is defined as the emergence of teeth from the jaws. When the pedicle banding the tooth germ to the dental lamina splits, the eruption process starts, and continues until the tooth reaches the occlusal position within the mouth. ${ }^{1}$ Any part of the tooth visible on the gingival surface is considered as the mark point of emergence. This period requires attention from healthcare professionals and can be challenging for parents. Other than being a process with many physical and psychological alterations, replete of typical signs and symptoms, it plays a key role in children's development and growth. ${ }^{2}$ The primary tooth eruption pattern could vary greatly and is influenced by a series of different factors. ${ }^{3}$

This disparity in deciduous tooth emergence in different studies may be related to different methodologies. Longitudinal and cross-sectional 
studies found dissimilar results; depending on the use of a clinical exam or interview, the definition of "erupted teeth" can be diverse and impact., ${ }^{4,5}$ However, many other physiological aspects might be involved in altering the deciduous tooth eruption time, such as the maternal fertile age, gestational time, cephalic perimeter, the baby's weight and length at birth, the baby's sex, eating habits, ethnicity, socioeconomic factors, and maternal habits. ${ }^{6,7,8}$

The number of teeth at a certain age can be an important parameter for evaluating the child development. ${ }^{6}$ In a cohort study, ${ }^{9}$ it was observed that the number of teeth that erupted at 15 months of age could be a marker of adolescent health, with those presenting more teeth in the oral cavity at a younger age having more odds of being overweight/obese teenagers. The number of teeth present at 6 and 12 months is also a marker for eruption of permanent teeth, and nutritional and developmental factors could influence the number of teeth erupted. ${ }^{6}$

Considering the need to understand this process and related factors, the objective of this study was to verify the pre-, peri-, and postnatal factors associated with the eruption of the first deciduous teeth in a cohort of live births using a longitudinal follow-up, and testing the hypothesis that these factors could influence tooth development and eruption.

\section{Methodology}

This study was nested in the 2015 Pelotas (Brazil) Birth Cohort Study, which is a larger study conducted in Pelotas, a southern Brazilian city. The 2015 Pelotas (Brazil) Birth Cohort is the fourth birth cohort of Pelotas, including all children born in the year 2015 from mothers who lived in the urban area of the city. By 2018, 5 follow-up studies were conducted: a) antenatal study (during pregnancy), b) perinatal study (at maternities), c) at 3 months of age, d) at 12 months of age, and e) at 24 months of age. The methodological aspects of this cohort study have been previously detailed. ${ }^{10}$

To collect data at each follow-up, approximately 40 interviewers with previous experience in epidemiological studies were trained. A theoretical-practical pre-training of 40 hours was realized in order to standardize the entire process of data collection. Interviewers underwent theoretical training and conducted experimental interviews in order to identify comprehension, difficulties, and inconsistencies in the instruments.

\section{Outcome variable: number of teeth at 12 months of age}

In the follow-up at 12 months of age, mothers were asked about the number of deciduous teeth the child had through the questions: a) How many teeth does your child have in the upper part of the mouth? b) How many teeth dose your child have in the lower part of the mouth? Mothers were instructed to consider elements that had only a small visible part as an erupted tooth. ${ }^{11}$ For the proposed analysis, a third variable considering all teeth at 12 months of age was raised. A validation study was also conducted to confirm the validity and reproducibility of the maternal report compared to the clinical examination.

\section{Independent variables}

\section{Maternal characteristics}

The mother's age was collected in continuous years and divided into three categories $(<20,20-34$, and 35-46 years). Skin color was self-reported and categorized as white or non-white. Maternal schooling was collected as complete continuous years of schooling and categorized as equal to or less than eight years and nine or more years of study, according to the Brazilian schooling system.

\section{Prenatal factors}

Prenatal factors included maternal morbidities, unhealthy habits, and weight gain during pregnancy. The occurrence of anemia, diabetes mellitus, arterial hypertension, and asthma during pregnancy were investigated through specific questions. Pregnant women were asked if they had anemia/diabetes mellitus/arterial hypertension/asthma during the antenatal period, with yes or no as possible response alternatives. Smoking habit, alcohol use, and illicit drug use during pregnancy were the variables related to unhealthy habits collected. Pregnant women were 
asked if they smoked or consumed alcohol or some illicit drug during pregnancy, with yes or no as possible response alternatives. For each unhealthy habit, one question was asked. Weight gain during pregnancy was evaluated according to the recommendations of the Institute of Medicine. ${ }^{12}$ The body mass index (BMI) was obtained from measurements carried out in antenatal care facilities. For women with a low BMI (BMI < 18.5 kilograms $/$ metres $^{2}\left[\mathrm{~kg} / \mathrm{m}^{2}\right]$ ), normal BMI (BMI ranging from $18.5-25 \mathrm{~kg} / \mathrm{m}^{2}$ ), those who were overweight (BMI higher than $\left.25-30 \mathrm{~kg} / \mathrm{m}^{2}\right)$, and obese $\left(\mathrm{BMI}>30 \mathrm{~kg} / \mathrm{m}^{2}\right)$, the expected weight gain during pregnancy ranged from $13-18 \mathrm{~kg}, 11.5-16 \mathrm{~kg}, 7-11.5 \mathrm{~kg}$, and $5-9 \mathrm{~kg}$, respectively. Weight gain within these ranges was considered adequate during pregnancy. Weight gain values below or above these parameters were classified as insufficient or excessive weight gain, respectively.

\section{Perinatal factors}

Perinatal factors included the gestational age at birth, Apgar score at the first and fifth minutes after delivery, the child's sex, and anthropometric measures at birth. All measurements were carried out by the medical team at the moment of birth. Gestational age was classified considering the date of the first day of the last menstrual period according to previous studies that analyzed such a same sample. ${ }^{13}$ The following categories were considered: a) early preterm (from 24 to < 34 weeks), b) late preterm ( 34 to $<37$ weeks), c) early term (37 weeks and 0/7 days to 38 weeks and 6/7 days), d) full term (39 weeks and $0 / 7$ days to 40 weeks and 6/7 days), e) late term (from 41 weeks and 0/7 days to 41 weeks and $6 / 7$ days), and f) post-term ( $\geq 42$ weeks and $0 / 7$ days). The Apgar score at the first and fifth minutes was categorized according to the American Academy of Pediatrics ${ }_{1}^{14}$ considering normal and intermediate values. Apgar scores were categorized into $0-3$ points, $4-6$ points, and $\geq 7$ points. Apgar at the fifth minute was categorized into $0-6$ and $\geq 7$ points. Anthropometric measures at birth including the weight, length, and head circumference were recorded as z-scores based on the gestational age of the child. We categorized the anthropometric measures based on the growth curves recommended by the World Health Organization (WHO). ${ }^{15}$ Birth weight $\mathrm{z}$-scores were classified as adequate $(-2$ to +2$)$, low $(>-3$ to $<-2)$, and high $(>+2)$. Birth length $\mathrm{z}$-scores were categorized as adequate $(\geq-2)$ or low $(>-2$ to $<-2)$. Head circumference $\mathrm{z}$-scores were categorized as adequate $(\leq+2 \mathrm{e} \geq-2)$, low $(>-2)$, or high $(>+2)$.

\section{Postnatal factors}

Postnatal factors included thethe age at which pacifier-use began exclusive breastfeeding up to 6 months of age, start of meat consumption, and anthropometric measures at 12 months of age. The American Academy of Pediatrics (AAP) ${ }^{16}$ recommends discontinuing pacifiers when children reach one year old and exclusively breastfeed until 6 months of age. Thus, the start time of pacifier use was categorized as "never used", "use from birth to 6 months" and "use from 7 to 12 months". Exclusive breastfeeding up to 6 months of age was recorded as "yes" or "no". The start time of meat consumption was categorized in view of AAP recommendations on the introduction of meat from six months of age in the 12-month follow-up period. Thus, this variable was marked as a) does not consume at 12 months of age, b) started to consume from to 0-5 months of age, c) started to consume at 6 months of age, and d) started to consume from 7 to 12 months of age. At 12 months of age, the z-scores for weight-for-age and length/height-for-age were calculated and classified according to the growth curves by WHO. ${ }^{15}$ Weight-for-age z-scores were classified into adequate $(-2$ to +2$)$, low $(>-3$ to $<-2)$, and high $(>+2)$. Length-for-age z-scores were categorized into adequate $(\geq-2)$ and low $(>-2$ to $<-2)$. Head circumference at 12 months was used as a continuous variable in the statistical analysis. These anthropometric measurements of babies visiting the Cohort Clinic at the Center for Epidemiology, Federal University of Pelotas at 3 and 12 months of age were collected by trained personnel.

\section{Ethical considerations}

The Human Research Ethics Committee of the Federal University of Pelotas, Faculty of Medicine, approved this study under Protocol number 717.271. 


\section{Data analysis}

Statistical analyses were performed using Stata 14.0 (Stata Corporation, College Station, Texas, USA). Initially, a descriptive analysis of the total sample presenting absolute and relative frequencies with their respective $95 \%$ confidence intervals was performed. The outcome (number of teeth at 12 months of age) was used as a continuous variable. In order to explore possible associations between the outcome and independent variables considering the pre-, peri- and post-natal periods, crude and adjusted Poisson regression models were employed. Independent variables were ordered in five blocks to determine their entrances in the model. Magnitudes of associations between independent variables and outcomes were estimated using the incidence rate ratio (IRR) and 95\% confidence intervals (CI). A significance level of 0.05 was adopted.

\section{Results}

This study included 4,014 children belonging to the 2015 Pelotas birth cohort. The number of teeth at 12 months of age varied from 0 to 20 teeth with a mean of 5.5 (SD 2.8). Boys had a mean of 5.8 (SD 2.7) erupted teeth, with a mean of 3.0 (SD 1.7) maxillary and 2.8 (SD 1.3) mandibular teeth. Girls had a mean of 5.2 (SD 2.8) erupted teeth, with a mean of 2.6 (SD 1.8) maxillary and 2.6 (SD 1.3) mandibular teeth (data not shown).

Table 1 shows the descriptive analysis, considering the socioeconomic and demographic characteristics, anthropometric measurements, and health behaviors of participants. Most of the mothers were aged 20-34 years $(72.2 \%)$, white $(70.8 \%)$, and had studied for nine or more years $(65.5 \%)$. With regard to the gestational period, most mothers did not smoke $(83.9 \%)$ or consume alcohol $(92.7 \%)$ or illicit drugs $(98.9 \%)$. However, most mothers had an excessive weight gain during pregnancy (35.7\%). Boys comprised $50.8 \%$ of the sample. Forty percent of the children were born full term (40.1\%), and more than $90 \%$ presented high Apgar scores (above 7). More than $90 \%$ of children presented with an adequate birth weight (94.6\%) and adequate birth length (95.1\%). About $64 \%$ of the children had an adequate birth head circumference (64.4\%). In relation to the characteristics of children from 3 to 12 months of age, most children started to use pacifiers from birth to six months of age $(60 \%)$, exclusively breastfeeding up to six months of age (79.3\%) and started consuming meat at seven months of age $(48.2 \%)$. When anthropometric measures were assessed, most children presented an adequate weight for age at 12 months (90\%) and adequate length for age at the 12 months (96.1\%). The mean head circumference at 12 months of age was 45.8 centimeters.

Table 2 shows the crude and adjusted Poisson regression model considering the children's number of teeth at 12 months of age as outcome and the weight $\mathrm{z}$-score at birth and at 12 months of age as exposure variables. After adjustments, children from non-white mothers (IRR 0.94; 95\% CI 0.91-0.98) presented a lower number of teeth at 12 months of age. Children whose mothers smoked and gained excessive weight during gestation had an incidence rate of 10\% (IRR 1.10; 95\%CI 1.05-1.16) and 5\% (IRR 1.05; 95\%CI 1.01-1.09), and a higher number of teeth, respectively. Children born in early preterm presented a lower number of teeth in the mouth at 12 months compared to those of all other gestational periods. Girls exhibited lesser teeth (IRR 0.91; 95\%CI 0.87-0.94) compared to boys. Bigger children at birth (IRR 1.13; 95\%CI 1.07-1.20) and at 12 months of age (IRR 1.14; 95\%CI 1.07-1.20) presented a higher number of teeth.

Shorter children at birth and 12 months presented the same decrease of $14 \%$ in the incidence rate of mean teeth at 12 months of age (IRR 0.86; 95\% CI 0.77-0.96). A higher cephalic perimeter at birth (IRR 1.05; 95\%CI 1.01-1.09) and at 12 months of age (IRR 1.04; 95\%CI1.02-1.05) were associated with a higher number of teeth at 12 months of age.

\section{Discussion}

This exploratory study investigated factors associated with the number of teeth at 12 months of age. Our findings support the hypothesis that the number of teeth in the first year of the child's life is influenced during the pre-, peri-, and post-natal periods.

Children of mothers with social deprivation are more likely to have advanced dental development. ${ }^{17}$ Although the mechanism of this association is not clear, it is a cause of concern, since an association between 
Table 1. Descriptive analysis of total sample considering socioeconomic and demographic characteristics, anthropometric measures and health behaviors in children population. Pelotas, RS, Brazil ( $n=4,014$ children).

\begin{tabular}{|c|c|}
\hline Variables & $\mathrm{n}(\%)[95 \% \mathrm{Cl}]$ \\
\hline \multicolumn{2}{|l|}{ Pre-pregnancy period } \\
\hline \multicolumn{2}{|l|}{ Block 1 - Maternal characteristics } \\
\hline Mother's age & 3,068 \\
\hline$<20$ years & 433 (14.1) [12.89-15.39] \\
\hline $20-34$ years & $2,216(72.2)[70.60-73.80]$ \\
\hline $35-46$ years & 419 (13.7) [12.46-14.92] \\
\hline Skin color (self-reported) & 3,065 \\
\hline White & $2,169(70.8)$ [69.12-72.37] \\
\hline Non-white & $896(29.2)$ [27.62-30.87] \\
\hline Maternal schooling & 4,013 \\
\hline$\leq 8$ years & $1,379(34.4)$ [32.89-35.85] \\
\hline$\geq 9$ years & $2,634(65.6)$ [64.14-67.10] \\
\hline \multicolumn{2}{|l|}{ Block 2 - Pre-pregnancy morbidities } \\
\hline Anemia & 3,044 \\
\hline No & $2,021(66.4)[64.68-68.07]$ \\
\hline Yes & $1,023(33.6)[31.92-35.31]$ \\
\hline Diabetes mellitus & 3,063 \\
\hline No & $2,990(97.6)[97.01-98.12]$ \\
\hline Yes & $73(2.4)[1.87-2.98]$ \\
\hline Arterial hypertension & 3,064 \\
\hline No & $2,536(82.8)$ [81.38-84.08] \\
\hline Yes & $528(17.2)$ [15.91-18.61] \\
\hline Asthma & 3,066 \\
\hline No & $2,582(84.2)$ [82.87-85.48] \\
\hline Yes & $484(15.8)[14.51-17.12]$ \\
\hline \multicolumn{2}{|l|}{ Pregnancy period } \\
\hline \multicolumn{2}{|l|}{ Block 3 - Health behaviors } \\
\hline Smoking habit during pregnancy & 4,011 \\
\hline No & 3,365 (83.9) [82.71-85.02] \\
\hline Yes & $646(16.1)$ [14.98-17.28] \\
\hline Alcohol use & 4,011 \\
\hline No & 3,716 (92.7) [91.79-93.43] \\
\hline Yes & $295(7.3)[6.56-8.21]$ \\
\hline Illicit drugs use & 3,014 \\
\hline No & $2,980(98.9)$ [98.42-99.21] \\
\hline Yes & $34(1.1)[0.78-1.57]$ \\
\hline Weight gain during pregnancy & 3,863 \\
\hline Adequate weight gain & $1,314(34.0)[32.5-35.5]$ \\
\hline Insufficient weight gain & 1,169 (30.3) [28.8-31.7] \\
\hline Excessive weight gain & $1,380(35.7)] 34.2-37.2]$ \\
\hline \multicolumn{2}{|l|}{ Perinatal period } \\
\hline \multicolumn{2}{|l|}{ Block 4 - Birth children characteristics } \\
\hline Gestational age & 4,014 \\
\hline Early preterm & $148(3.7)[3.1-4.3]$ \\
\hline Late preterm & 440 (11) [10.0-11.9] \\
\hline Early term & 1,499 (37.3) [35.8-38.8] \\
\hline Full term & $1,611(40.1)[38.6-41.6]$ \\
\hline Late term & $287(7.2)[6.3-7.9]$ \\
\hline Post-term & $29(0.7)[0.4-1.0]$ \\
\hline
\end{tabular}


Wich factors influencing the number of teeth at 12 months of age: a birth cohort study

\begin{tabular}{|c|c|}
\hline Variables & $\mathrm{n}(\%)[95 \% \mathrm{Cl}]$ \\
\hline Apgar $1^{\circ}$ minute & 4,001 \\
\hline $0-3$ & $112(2.8)[2.31-3.35]$ \\
\hline $4-6$ & $240(6)[5.28-6.77]$ \\
\hline$\geq 7$ & $3,649(91.2)$ [90.28-92.06] \\
\hline Apgar $5^{\circ}$ minute & 4,003 \\
\hline $0-6$ & $35(0.9)[0.60-1.21]$ \\
\hline$\geq 7$ & $3,968(99.1)$ [98.78-99.39] \\
\hline Gender & 4,014 \\
\hline Male & $2,040(50.8)[49.26-52.38]$ \\
\hline Female & $1,974(49.2)[47.61-50.73]$ \\
\hline Birth weight/gestational age (score-z) & 4,011 \\
\hline Adequate & $3,788(94.6)[93.8-95.2]$ \\
\hline Low & $62(1.5)[0.1-1.9]$ \\
\hline High & $156(3,9)[3.3-4.5]$ \\
\hline Birth lenght/gestational age (score-z) & 4.001 \\
\hline Adequate & $3806(95.1)[94.4-95.7]$ \\
\hline Low & $195(4.9)[4.2-5.6]$ \\
\hline Birth head circumference/gestational age (score-z) & 4.001 \\
\hline Adequate & $2.574(64.4)[62.8-65.8]$ \\
\hline Low & $393(9.8)[8.9-10.7]$ \\
\hline High & $1034(25,8)[24.4-27.2]$ \\
\hline \multicolumn{2}{|c|}{ Block 5 - Children characteristics from 3 to 12 months of age } \\
\hline Start time of pacifier use & 4.014 \\
\hline Never used & $1.509(37.6)[36.1-39.1]$ \\
\hline $0-6$ months of age & $2.409(60.0)[58.4-61.5]$ \\
\hline $7-12$ months of age & $96(2.4)[1.9-2.9]$ \\
\hline Exclusive breastfeeding up to 6 months of age & 3,964 \\
\hline No & 819 (20.7) [19.41-21.95] \\
\hline Yes & 3,145 (79.3) [78.04-80.59] \\
\hline Start of meat consumption (at 12-month follow up) & 4,009 \\
\hline Do not consume & 319 (8) [7.13-8.83] \\
\hline $0-5$ months of age & 472 (1 1.8) [10.79-12.81] \\
\hline 6 months of age & $1,291(32.2)[30.75-33.67]$ \\
\hline $7-12$ months of age & $1,927(48.2)[46.51-49.62]$ \\
\hline Weight-for-age z-score at 12 months & 3,957 \\
\hline Adequate & $3,523(90.0)[89.1-90.9]$ \\
\hline Low weight & $60(1.5)[1.1-1.9]$ \\
\hline High weight & $334(8.5)[7.59-9.35]$ \\
\hline Length/height-for-age z-score at 12 months & 3,958 \\
\hline Low length & 156 (3.9) [3.35-4.59] \\
\hline Adequate length & $3,802(96.1)$ [95.40-96.64] \\
\hline Head circumference at 12 months & 3,949 \\
\hline Mean (continuous)/ in centimeters $(\mathrm{cm})$ & $45.8 \mathrm{~cm}(40$ to 57.1$)$ \\
\hline
\end{tabular}

*statistical significant $p$-value $\leq 0.05$. 
Table 2. Association between number of teeth at 12 months of age and independent variables considering socioeconomic and demographic characteristics, anthropometric measures and health behaviors in children population. Multivariate analysis: Poisson Regression. Pelotas, RS, Brazil ( $\mathrm{n}=4,014$ children).

\begin{tabular}{|c|c|c|c|c|}
\hline \multirow{3}{*}{ Variables } & \multicolumn{4}{|c|}{ Number of teeth at 12 months of age } \\
\hline & \multirow{2}{*}{$\begin{array}{l}\text { Bivariate analysis } \\
\text { IRR }(95 \% \mathrm{CI})\end{array}$} & \multirow{2}{*}{ p-value* } & \multirow{2}{*}{$\begin{array}{c}\text { Multivariate analysis } \\
\text { IRR }(95 \% \mathrm{CI})\end{array}$} & \multirow{2}{*}{ p-value* } \\
\hline & & & & \\
\hline \multicolumn{5}{|l|}{ Pre-pregnancy period } \\
\hline \multicolumn{5}{|l|}{ Block 1 - Maternal characteristics } \\
\hline Mother's age (ref. <20 years) & & 0.231 & - & -- \\
\hline 20-34 years & $0.94(0.89-0.98)$ & & & \\
\hline $35-46$ years & $0.96(0.90-1.03)$ & & & \\
\hline Skin color (self-reported) (ref. White) & & 0.059 & & 0.007 \\
\hline Non-white & $0.96(0.92-1.00)$ & & $0.94(0.91-0.98)$ & \\
\hline Maternal schooling (ref. $\geq 8$ years) & & 0.004 & & 0.113 \\
\hline$\leq 8$ years & $1.05(1.01-1.08)$ & & $1.03(0.99-1.08)$ & \\
\hline \multicolumn{5}{|l|}{ Block 2 - Pre-pregnancy morbidities } \\
\hline Anemia (ref. No) & & 0.848 & & \\
\hline Yes & $0.99(0.96-1.03)$ & & & \\
\hline Diabetes mellitus (ref. No) & & 0.049 & - & -- \\
\hline Yes & $1.05(1.00-1.12)$ & & & \\
\hline Arterial hypertension (ref. No) & & 0.333 & & \\
\hline Yes & 1.01 (0.98-1.05) & & & \\
\hline Asthma (ref. No) & & 0.344 & & \\
\hline Yes & $1.02(0.97-1.06)$ & & & \\
\hline \multicolumn{5}{|l|}{ Pregnancy period } \\
\hline \multicolumn{5}{|l|}{ Block 3 - Health behaviors } \\
\hline Smoking habit during pregnancy period (ref. No) & & $<0.001$ & & $<0.001$ \\
\hline Yes & $1.08(1.03-1.12)$ & & $1.10(1.05-1.16)$ & \\
\hline Alcohol use (ref. No) & & 0.472 & & \\
\hline Yes & $1.01(0.97-1.05)$ & & & \\
\hline Illicit drugs use (ref. No) & & 0.010 & & 0.196 \\
\hline Yes & $1.20(1.04-1.38)$ & & $1.09(0.95-1.26)$ & \\
\hline Weight gain during pregnancy (ref. Adequate) & & 0.006 & & 0.014 \\
\hline Insufficient weight gain & $0.97(0.93-1.02)$ & & $0.98(0.94-1.03)$ & \\
\hline Excessive weight gain & $1.05(1.01-1.11)$ & & $1.05(1.01-1.09)$ & \\
\hline \multicolumn{5}{|l|}{ Perinatal period } \\
\hline \multicolumn{5}{|l|}{ Block 4 - Birth children characteristics } \\
\hline Gestational age (ref. early preterm) & & $<0.001$ & & $<0.001$ \\
\hline Late preterm & $1.23(1.10-1.39)$ & & $1.22(1.06-1.39)$ & \\
\hline Early term & $1.22(1.10-1.36)$ & & $1.23(1.09-1.39)$ & \\
\hline Full term & $1.27(1.14-1.41)$ & & $1.28(1.13-1.45)$ & \\
\hline Late term & $1.39(1.24-1.56)$ & & $1.38(1.20-1.58)$ & \\
\hline Post-term & $1.18(0.94-1.48)$ & & $1.32(1.10-1.59)$ & \\
\hline Apgar $1^{\circ}$ minute (ref. $\geq 7$ ) & & 0.623 & & \\
\hline $0-6$ & $0.94(0.86-1.03)$ & & & \\
\hline $0-3$ & $1.02(0.96-1.09)$ & & & \\
\hline Apgar $5^{\circ}$ minute (ref. $\geq 7$ ) & & 0.990 & & \\
\hline $0-6$ & $1.00(0.86-1.16)$ & & & \\
\hline
\end{tabular}




\begin{tabular}{|c|c|c|c|c|}
\hline \multirow{3}{*}{ Variables } & \multicolumn{4}{|c|}{ Number of teeth at 12 months of age } \\
\hline & \multirow{2}{*}{$\begin{array}{c}\text { Bivariate analysis } \\
\text { IRR }(95 \% \mathrm{CI})\end{array}$} & \multirow{2}{*}{$p$-value* } & \multirow{2}{*}{$\begin{array}{c}\text { Multivariate analysis } \\
\text { IRR }(95 \% \mathrm{Cl})\end{array}$} & \multirow{2}{*}{$\mathrm{p}$-value } \\
\hline & & & & \\
\hline Gender (ref. Male) & & $<0.001$ & & $<0.001$ \\
\hline Female & $0.91(0.87-0.93)$ & & $0.91(0.87-0.94)$ & \\
\hline Weight z-score (Intergrowth 21 -reference adequate) & & 0.001 & & 0.021 \\
\hline Low & $0.88(0.77-1.01)$ & & $0.89(0.76-1.04)$ & \\
\hline High & $1.15(1.07-1.23)$ & & $1.13(1.07-1.20)$ & \\
\hline Length z-score (Intergrowth 21 -reference adequate) & & $<0.001$ & & 0.003 \\
\hline Low very low & $0.85(0.78-0.93)$ & & $0.86(0.77-0.96)$ & \\
\hline Head circumference z-score (Intergrowth 21 -reference adequate -1 até 1 ) & & $<0.001$ & & 0.051 \\
\hline Low & $0.89(0.84-0.95)$ & & $0.96(0.89-1.03)$ & \\
\hline High & $1.09(1.05-1.13)$ & & $1.05(1.01-1.09)$ & \\
\hline \multicolumn{5}{|l|}{ Block 5 - Children characteristics from 3 to 12 months of age } \\
\hline Start time of pacifier use (ref. Do not use) & & 0.058 & & 0.079 \\
\hline At birth to 6 months of age & $0.95(0.92-0.98)$ & & $0.94(0.91-0.97)$ & \\
\hline $7-12$ months of age & $1.08(0.98-1.19)$ & & $1.12(1.01-1.24)$ & \\
\hline Exclusive breastfeeding up to 6 months of age (ref. No) & & 0.303 & & \\
\hline Yes & $1.02(0.98-1.06)$ & & & \\
\hline Consumption of meat (ref. Do not consume) & & 0.041 & & 0.271 \\
\hline $0-5$ months of age & $1.15(1.06-1.24)$ & & $1.13(1.04-1.23)$ & \\
\hline 6 months of age & $1.07(1.00-1.14)$ & & $1.06(0.98-1.15)$ & \\
\hline $7-12$ months of age & $1.11(1.04-1.18)$ & & $1.09(1.01-1.17)$ & \\
\hline Weight-for-age z-score at 12 months (ref. Adequate/[-2 to +2]) & & $<0.001$ & & $<0.001$ \\
\hline Low weight $(S D>-3$ to $<-2)$ & $0.89(0.76-1.06)$ & & $0.98(0.80-1.21)$ & \\
\hline High weight $(>+2)$ & $1.17(1.11-1.22)$ & & $1.14(1.07-1.20)$ & \\
\hline Length/height-for-age z-score at 12 months (ref. Adequate length (SD $\leq-2$ ) & & $<0.001$ & & 0.008 \\
\hline Low length $[S D>-2$ to $<-2])$ & $0.81(0.74-0.89)$ & & $0.86(0.77-0.96)$ & \\
\hline Head circumference at 12 months (ref 0 , continuous) & & $<0.001$ & & $<0.001$ \\
\hline Mean $45,8 \mathrm{~cm}$ & $1.04(1.03-1.05)$ & & $1.04(1.02-1.05)$ & \\
\hline
\end{tabular}

${ }^{*}$ statistical significant $p$-value $\leq 0.05$.

higher levels of dental caries and earlier primary teeth eruption has been described. ${ }^{18}$ Differences in permanent tooth eruption related to skin color have already been shown, with black children being more precocious at the beginning of the process. ${ }^{10,19}$ However, few studies have investigated the influence of skin color on primary tooth eruption, and the results are still conflicting, with no influence ${ }^{6}$ or increasing the number of teeth in some ethnic background ${ }^{21}$ or decreasing in others. ${ }^{8,17}$ Our findings showed that having a non-white mother was associated with a lower number of children's teeth at 12 months of age. Studies investigating the influence of ethnicity present only speculative explanations for this association, pointing at factors such as genetic issues and environmental issues, such as nutrition or prenatal aspects. ${ }^{21}$ However, non-Hispanic black women are most likely to experience preterm birth, hypertensive disease of pregnancy, and small for gestational age births, ${ }^{22}$ which could partially explain the association.

Smoking during pregnancy is an important issue because it has been mentioned as one of the most robust and consistent predictors of primary tooth emergence patterns. ${ }^{17}$ Our results related to smoking habit are consistent with those found previously in the literature, ${ }^{17,23,24}$ with smoking habits during the gestational period linked to an increased number of teeth at 12 months of age. The mechanism linking 
tooth eruption to maternal smoking still needs to be clarified; however, it is already known that nicotine can pass through the placental barrier, which leads to elevated concentrations of this alkaloid in fetal tissues and generalized hypoxia. ${ }^{25}$ Infants of women who smoke during pregnancy have a lower whole bone mineral content and bone mineral density. Another possible explanation for this major implication in fetal bone is the action of cadmium, a substance present in tobacco, which affects the function of osteoblasts and trophoblasts. ${ }^{26}$

Our results showed that excessive maternal weight gain during pregnancy is related to a higher number of teeth in 12-month-old children. Ntani et al. ${ }^{17}$ observed that children whose mothers had a higher BMI during pregnancy were more likely to have a higher number of teeth at 12 months and were more prone to be dentally advanced at 24 months of age. The Institute of Medicine (IOM) recommends weight gain guidelines based on the pre-pregnancy body mass index (BMI). Excessive gestational weight gain increases the risks of many negative consequences for the fetus such as childhood obesity, higher fat mass at birth, and adverse cardiometabolic and cognitive-related outcomes ${ }^{27}$. Gestational weight gain might influence primary tooth eruption, and might be related to the number of teeth in the child A weight gain than the the recommended value can be related to preterm births and low birth weights, while excessive weight gain, especially in early pregnancy, is associated with a higher child $\mathrm{BMI}^{27}$ and even macrosomia. ${ }^{28}$ Our study showed an association between gestational age at birth and the number of teeth at 12 months of age, demonstrating that even smaller gestational age differences from early preterm to late preterm influence primary tooth eruption. Prematurity is strictly related to a child's anthropometric measures, which are already stated in the literature as predictors of tooth emergence. However, a cohort study ${ }^{6}$ found no relationship between preterm birth and the number of teeth that emerged at 12 months. In opposite, Viscardi et al., ${ }^{29}$ considering the corrected age, found that $60 \%$ of premature children had a late tooth eruption. Pavicin et al. ${ }^{30}$ and Ramos et al. ${ }^{31}$ found significant late eruption in premature children when chronological age was considered. Nonetheless, when gestational age was corrected, in both studies, the association lost significance.

All anthropometric measures at birth and at 12 months of age were significantly related to the number of teeth at 12 months of age, which corroborates with previous studies. A classical longitudinal study developed in 1987 by Ounsted et al., ${ }^{23}$ which followed children from birth to three years, found that all of the anthropometric measures evaluated (weight, height, and cephalic perimeter) were associated with the number of erupted primary teeth. Correa-Faria et al. ${ }^{32}$ performed oral clinical exams and anthropometric measurements (weight and height) of children between four and thirty months of age; after adjusting the multivariate regression model, only weight remained associated with the number of erupted teeth, and heavier children exhibited a higher number of teeth. In our study, heavier children were associated with a higher number of teeth, corroborating previous findings. ${ }^{7,23,33}$

In contrast, shorter children exhibited a lower incidence rate of teeth at 12 months of age. Gaur and Kumar, ${ }^{7}$ found that height in older children is the most important predictor of the number of teeth, with stunted children having a significantly greater likelihood of delayed eruption of primary teeth.

Children with a faster weight or height growth trajectory are expected to have advanced primary teeth emergence. ${ }^{17}$ There relationship between height and cephalic perimeter with dental development may be explained by the fact that dentition is a skeletal element and is likely to be stimulated by similar factors as those that induce skeletal growth. ${ }^{7}$ Children's weight at birth has been pointed out as an important marker of intrauterine growth and nutrition ${ }^{17}$ and inadequate nutritional status in early life; it is known to affect many aspects of the latter metabolism ${ }^{8}$, which could affect stomatognatic development.

Considering the close relationship between the anthropometric measures of the child and the eruption of deciduous teeth, this process can be pointed out as an important marker of nutritional status and of the child's growth and development ${ }^{8}$. Even weight gain in early life is associated with eruption of the 
deciduous dentition ${ }^{8}$. It is important to emphasize that accelerated weight gain in early life may also be involved in the genesis of many alterations such as obesity, diabetes, hypertension, and other metabolic syndromes. For instance, accelerated primary tooth emergence could be important in predicting pathologies in adulthood. A longitudinal cohort study evaluated the anthropometric indices of adolescents at age 17 and found that early eruption of deciduous teeth may be an important predictor of obesity in adolescence. ${ }^{9}$

In accordance with other studies, ${ }^{17,24,34}$ we found that girls tend to have fewer teeth at 12 months than boys. BurgueñoTorres et al. ${ }^{3}$ observed that except for the first molars and maxillary central incisors, all the primary teeth erupted earlier in boys. In this context, a cross-over pattern of developmental is often perceived in literature, with earlier posterior dentition in girls, and earlier anterior dentition in boys. ${ }^{34}$ This is consistent with our findings, since only anterior teeth had erupted for most of the children in this study.

The relationship between early emergence of primary teeth and dental caries occurrence is also a concern. ${ }^{35}$ It is possible that earlier tooth eruption has a negative impact on oral health, since it can affect the enamel quality. Ameloblasts are responsible for enamel formation, and when the tooth emerges, this process stops, ameloblasts are lost, and no further enamel remodeling is possible. Therefore, in children with accelerated tooth development, the eruption may occur before the tooth is completely mineralized, which can lead to the development of dental caries. ${ }^{17}$ Other authors have affirmed that the longer the dental element is in the mouth, the greater the risk of being affected by dental caries. ${ }^{18}$ Knowledge of the process of primary dental eruption is indispensable to guide those responsible for the dental care of children, and to establish adequate prevention actions, such as the application of fluoride and sealants. ${ }^{18}$

Some important strengths of this study should be highlighted. The present investigation was nested in a cohort study, which collected data right from pregnancy, enrolling more than 4,000 children. Longitudinal studies are the most adequate to investigate the effect of different expositions on a determined outcome. In addition, the data collected are more reliable, avoiding the occurrence of memory bias, since data are obtained closer to the event. This was one of the largest studies related to the topic, which reinforces our findings.

To classify birth and 12-month-old anthropometric measures, we used the z-score, which is the best system for analysis and presentation of anthropometric data for population-based assessment according to $\mathrm{WHO}^{15}$ The use of z-score enables comparability across age groups and indicators, and the scores are also sexindependent, so it is possible to evaluate children's growth status by combining sex and age groups. Normalization through the percentile or the z-score is essential for a better assessment of children's nutritional status. ${ }^{15}$

In addition, there are some limitations that should be discussed. The number of teeth was considered based on the mothers' counting and reporting to the interviewer, and no clinical examination was carried out by a trained professional.

Both maternal characteristics (smoking and weight gain during the gestational period) and the child's characteristics (gender, weight, height, and head circumference) influenced the number of teeth erupted during the first year of life. The number of erupted teeth may be an important indicator of children's development.

\section{Acknowledgment}

This study was financed in part by the Coordenação de Aperfeiçoamento de Pessoal de Nível Superior (CAPES), Brazil (Finance Code 001). This study is based on data from the "Pelotas Birth Cohort, 2015", a follow up conducted by Postgraduate Program in Epidemiology at Universidade Federal de Pelotas, with the collaboration of the Brazilian Public Health Association (ABRASCO). The 2015 Pelotas (Brazil) Birth Cohort is funded by the Wellcome Trust (095582). Funding for oral health follow-ups was provided to the PI (FFD) by Conselho Nacional de Desenvolvimento Científico e Tecnológico (CNPq) (\#454796/2014-5 and 426230/2018-3) and Fundação de Amparo a Pesquisa do Estado do Rio Grande do Sul (FAPERGS) - Pronex (\#160471-4). 
Silveira ER, Cademartori MG, Ardenghi TM, Silveira M, Barros FC, Azeedo MS, et al.

\section{References}

1. F Neto PG, Falcão MC. Eruption chronology of the first deciduous teeth in children born prematurely with birth weight less than $1500 \mathrm{~g}$. Rev Paul Pediatr. 2014;32(1):17-23. https://doi.org/10.1590/S0103-05822014000100004

2. Ramos-Jorge J, Pordeus IA, Ramos-Jorge ML, Paiva SM. Prospective longitudinal study of signs and symptoms associated with primary tooth eruption. Pediatrics. 2011 Sep;128(3):471-6. https://doi.org/10.1542/peds.2010-2697

3. Burgueño Torres L, Mourelle Martínez MR, Diéguez Pérez M, Nova García JM. Sexual dimorphism of primary dentition in Spanish children. Acta Odontol Scand. 2018 Nov;76(8):545-52. https://doi.org/10.1080/00016357.2018.1449963

4. Verma N, Bansal A, Tyagi P, Jain A, Tiwari U, Gupta R. Eruption chronology in children: a cross-sectional study. Int J Clin Pediatr Dent. 2017 Jul-Sep;10(3):278-82. https://doi.org/10.5005/ip-journals-10005-1450

5. Hulland SA, Lucas JO, Wake MA, Hesketh KD. Eruption of the primary dentition in human infants: a prospective descriptive study. Pediatr Dent. 2000 Sep-Oct;22(5):415-21.

6. Bastos JL, Peres MA, Peres KG, Barros AJ. Infant growth, development and tooth emergence patterns: A longitudinal study from birth to 6 years of age. Arch Oral Biol. 2007 Jun;52(6):598-606. https://doi.org/10.1016/j.archoralbio.2006.12.001

7. Gaur R, Kumar P. Effect of undernutrition on deciduous tooth emergence among Rajput children of Shimla District of Himachal Pradesh, India. Am J Phys Anthropol. 2012 May;148(1):54-61. https://doi.org/10.1002/ajpa.22041

8. Un Lam C, Hsu CS, Yee R, Koh D, Lee YS, Chong MF, et al. Early-life factors affect risk of pain and fever in infants during teething periods. Clin Oral Investig.

9. Fatemifar G, Evans DM, Tobias JH. The association between primary tooth emergence and anthropometric measures in young adults: findings from a large prospective cohort study. PLoS One. 2014 May;9(5):e96355. https://doi.org/10.1371/journal.pone.0096355

10. Hallal PC, Bertoldi AD, Domingues MR, Silveira MFd, Demarco FF, Silva ICM, et al. Cohort profile: the 2015 Pelotas (Brazil) birth cohort study. Int J Epidemiol. 2018 Aug;47(4):1048-48h. https://doi.org/10.1093/ije/dyx219

11. Holman DJ, Jones RE. Longitudinal analysis of deciduous tooth emergence: II. Parametric survival analysis in Bangladeshi, Guatemalan, Japanese, and Javanese children. Am J Phys Anthropol. 1998 Feb;105(2):209-30. https://doi.org/10.1002/(SICI)10968644(199802)105:2<209::AID-AJPA8>3.0.CO;2-P

12. Rasmussen KM, Yaktine AL, editors. Weight gain during pregnancy: reexamining the guidelines. Washington, DC: National Academies Press; 2009.

13. Coll C, Domingues M, Santos I, Matijasevich A, Horta BL, Hallal PC. Changes in leisure-time physical activity from the prepregnancy to the postpartum period: 2004 Pelotas (Brazil) Birth Cohort Study. J Phys Act Health. 2016 Apr;13(4):361-5. https://doi.org/10.1123/ipah.2015-0324

14. American Academy of Pediatrics Committee on Fetus, Newbornamerican College of Obstetricians and Gynecologists Committee on Obstetric Practice. The apgar score. Pediatrics. 2015 Oct;136(4):819-22. https://doi.org/10.1542/peds.2015-2651

15. WHO Multicentre Growth Reference Study Group. WHO Child Growth Standards based on length/height, weight and age. Acta Paediatr Suppl. 2006 Apr;450:76-85. https://doi.org/10.1111/j.1651-2227.2006.tb02378.x

16. Peres KG, Chaffee BW, Feldens CA, Flores-Mir C, Moynihan P, Rugg-Gunn A. breastfeeding and oral health: evidence and methodological challenges. J Dent Res. 2018 Mar;97(3):251-258. https://doi.org/10.1177/0022034517738925

17. Ntani G, Day PF, Baird J, Godfrey KM, Robinson SM, Cooper C, et al.; Southampton Women's Survey Study Group. Maternal and early life factors of tooth emergence patterns and number of teeth at 1 and 2 years of age. J Dev Orig Health Dis. 2015 Aug;6(4):299-307. https://doi.org/10.1017/S2040174415001130

18. Gupta A, Hiremath SS, Singh SK, Poudyal S, Niraula SR, Baral DD, et al. Emergence of primary teeth in children of Sunsari district of Eastern Nepal. Mcgill J Med. 2007 Jan;10(1):11-5.

19. De Melo MJ, Freitas E, Salzano FM. Eruption of permanent teeth in Brazilian whites and blacks. Am J Phys Anthropol. 1975 Jan;42(1):145-50. https://doi.org/10.1002/ajpa.1330420118

20. Kanagaratnam S, Schluter PJ. The age of permanent tooth emergence in children of different ethnic origin in the Auckland region: a cross-sectional study. N Z Dent J. 2012 Jun;108(2):55-61.

21. Warren JJ, Fontana M, Blanchette DR, Dawson DV, Drake DR, Levy SM, et al. Timing of primary tooth emergence among U.S. racial and ethnic groups. J Public Health Dent. 2016 Sep;76(4):259-62. https://doi.org/10.1111/iphd.12154

22. Grobman WA, Parker CB, Willinger M, Wing DA, Silver RM, Wapner RJ, et al. Racial disparities in adverse pregnancy outcomes and psychosocial stress. Obstet Gynecol. 2018 Feb;131(2):328-35. https://doi.org/10.1097/AOG.0000000000002441

23. Ounsted M, Moar V, Scott A. A longitudinal study of tooth emergence and somatic growth in 697 children from birth to three years. Arch Oral Biol. 1987;32(11):787-91. https://doi.org/10.1016/0003-9969(87)90004-5

24. Żadzińska E, Sitek A, Rosset I. Relationship between pre-natal factors, the perinatal environment, motor development in the first year of life and the timing of first deciduous tooth emergence. Ann Hum Biol. 2016;43(1):25-33. 
25. Shea AK, Steiner M. Cigarette smoking during pregnancy. Nicotine Tob Res. 2008 Feb;10(2):267-78. https://doi.org/10.1080/14622200701825908

26. Godfrey K, Walker-Bone K, Robinson S, Taylor P, Shore S, Wheeler T, et al. Neonatal bone mass: influence of parental birthweight, maternal smoking, body composition, and activity during pregnancy. J Bone Miner Res. 2001 Sep;16(9):1694-703. https://doi.org/10.1359/jbmr.2001.16.9.1694

27. Gaillard R, Santos S, Duijts L, Felix JF. Childhood health consequences of maternal obesity during pregnancy: a narrative review. Ann Nutr Metab. 2016;69(3-4):171-80. https://doi.org/10.1159/000453077

28. Tian $C, H \cup C, H e X$, Zhu M, Qin F, Liu Y, et al. Excessive weight gain during pregnancy and risk of macrosomia: a meta-analysis. Arch Gynecol Obstet. 2016 Jan;293(1):29-35. https://doi.org/10.1007/s00404-015-3825-8

29. Viscardi RM, Romberg E, Abrams RG. Delayed primary tooth eruption in premature infants: relationship to neonatal factors. Pediatr Dent. 1994 Jan-Feb;16(1):23-8.

30. Pavičin IS, Dumančić J, Badel T, Vodanović M. Timing of emergence of the first primary tooth in preterm and full-term infants. Ann Anat. 2016 Jan;203:19-23. https://doi.org/10.1016/i.aanat.2015.05.004

31. Ramos SR, Gugisch RC, Fraiz FC. The influence of gestational age and birth weight of the newborn on tooth eruption. J Appl Oral Sci. 2006 Aug;14(4):228-32. https://doi.org/10.1590/S1678-77572006000400003

32. Corrêa-Faria P, Leite-Faria L, Viana AN, Marques LS, Ferreira FO, Ramos-Jorge ML. Factors associated with number of erupted primary teeth in Brazilian children: a cross-sectional study. J Dent Child (Chic). 2013 Sep-Dec;80(3):111-4.

33. Khalifa AM, El Gendy RA, El-Mohsen MM, Hammour AA, Aly RS. Relationship between gestational age, birth weight and deciduous tooth eruption. Egyptian Pediatric Association Gazette. 2014;62(2):41-5. https://doi.org/10.1016/i.epag.2014.04.001

34. Holman DJ, Jones RE. Longitudinal analysis of deciduous tooth emergence: III. Sexual dimorphism in Bangladeshi, Guatemalan, Japanese, and Javanese children. Am J Phys Anthropol. 2003 Nov;122(3):269-78. https://doi.org/10.1002/ajpa.10239

35. Ferro R, Besostri A, Olivieri A. Caries prevalence and tooth surface distribution in a group of 5-year-old Italian children. Eur Arch Paediatr Dent. 2009 Jan;10(1):33-7. https://doi.org/10.1007/BF03262665 